Original Research Paper

\title{
Drinking Wine at Home: Hedonic Analysis of Sicilian Wines Using Quantile Regression
}

\author{
${ }^{1}$ Giuseppe Di Vita, ${ }^{2}$ Francesco Caracciolo, ${ }^{2}$ Luigi Cembalo, ${ }^{2}$ Eugenio Pomarici and ${ }^{1}$ Mario D'Amico \\ ${ }^{I}$ Department of Agri-Food and Environmental Systems Management, University of Catania, Catania, Italy \\ ${ }^{2}$ Department of Agriculture, Agricultural Economics and Policy Group, University of Naples Federico II, Naples, Italy
}

Article history

Received: 27-09-2014

Revised: 29-01-2015

Accepted: 20-03-2015

Corresponding Author: Giuseppe Di Vita Department of Agri-Food and Environmental Systems Management, University of Catania, Catania, Italy Email: gvitae@hotmail.com

\begin{abstract}
In recent decades, the Sicilian wine industry has experienced a booming expansion because of the growing preferences of Italian consumers for Sicilian wines, especially in extra-regional markets. These consumers have been paying closer attention to Sicilian premium wines. For this reason, the objective of this study is to inform professional investors and wine managers about the consumer preferences with respect to the most important segment categories of domestically consumed Sicilian wines. Using the quantile regression technique, we analyzed the role of wine attributes and prices as an information tool in order to value for each wine segment the implicit price of the attributes affecting wine consumers' choices. The results indicate that Protected Designation of Origin (PDO) and Geographical Indication (PGI) certification is the main determinant in the wine price mechanisms and certified wines achieve premium prices that are progressively higher as the price level of the wine increases. Furthermore the effect of the brand on price formation seems to have a significant impact for low-end wines, whereas it has no specific impact on the price mechanism for high-end wines.
\end{abstract}

Keywords: Consumer Scan Dataset, Geographic Origin, Hedonic Price, Robust Regression, Wine Consumption

\section{Introduction}

In recent decades, the Sicilian wine industry has experienced a booming expansion because of the growing preferences of Italian consumers for Sicilian wines, especially in extra-regional markets. This trend is confirmed by the significant growth of wine bottlers over this period. They have increased from around 90 to over 630 bottlers in 2010 . Bottled wine production has almost tripled over this period to about 200 million bottles in 2010 (D'Amico et al., 2011).

Italian consumers have been increasingly paying attention to Sicilian wines and their importance has been highlighted in recent studies carried out both on consumers (Caniglia et al., 2008; Roma et al., 2013; Di Vita et al., 2014a) and wineries (Bellia, 2007; Di Vita et al., 2013a; Chinnici et al., 2013). As shown in Table 1, Sicily has a high potential for wine growth, which becomes even more significant if compared with the potential of other regions. Sicily is the fourth largest region in terms of its traded wines and its market share represents $8.7 \%$ of the national domestic consumption.

The main market for Sicilian wines is regional but recently a growing share in the national market has been observed. During the period between 2006 and 2011, the domestic market share of Sicilian wines has more than doubled (Table 2). Sicily's market share growth rate is one of the highest after those of the Trentino and Abruzzo regions; the leadership of these two regions is due to the leading role of their most renowned wines, such as Prosecco and Montepulciano d'Abruzzo.

The most important part of the sales of Sicilian wine is within the Protected Geographical Indication (PGI) classification, $85.4 \%$ of Sicilian wine traded is classified as PGI and it mostly takes place through large distribution channels (84.7\%). Lombardy, Latium and Emilia Romagna are the most important market destinations of Sicilian wines (source AC NIELSEN, 2011).

The appeal of Sicilian wines is also confirmed by the increasing sales of bottled wine in the extra-regional market; in the past decade, these exports have experienced an extraordinary increase in volume and value. The Sicilian wine industry produces a large variety of wines, ranging from premium to basic varieties, including bulk wines (Di Vita et al., 2014b). The diverse range of Sicilian wines (packaging, brand and PDO or PGI designations) enables consumers to choose among highly differentiated and segmented wines. 
Table 1. Domestic market share and average prices of Italian wines by region

\begin{tabular}{|c|c|c|c|c|c|c|c|}
\hline \multirow[b]{2}{*}{ Region } & \multicolumn{2}{|l|}{2011} & \multicolumn{2}{|l|}{2006} & \multirow{2}{*}{\begin{tabular}{l} 
Market difference \\
\hdashline $2011 / 2006$
\end{tabular}} & \multirow{2}{*}{$\begin{array}{l}\text { Price difference } \\
------- \\
\text { 2010/2005 } \\
\end{array}$} & \multirow[b]{2}{*}{ Rank 2006} \\
\hline & Market share $(\%)$ & Price (euro) & Market share $(\%)$ & Price (euro) & & & \\
\hline Emilia Romagna & 11.1 & 2.3 & 9.4 & 2.6 & 19.1 & -13.2 & 3 \\
\hline Veneto & 10.9 & 2.9 & 5.7 & 2.0 & 90.7 & 42.6 & 6 \\
\hline Tuscany & 9.3 & 4.5 & 7.0 & 2.4 & 33.3 & 85.5 & 5 \\
\hline Sicily & 8.7 & 3.3 & 4.5 & 1.7 & 92.9 & 94.5 & 8 \\
\hline Piedmont & 6.6 & 3.9 & 9.4 & 2.2 & -29.6 & 81.5 & 2 \\
\hline Apulia & 6.1 & 2.8 & 4.1 & 1.7 & 47.1 & 71.9 & 10 \\
\hline Lombardy & 5.9 & 3.5 & 9.6 & 2.7 & -38.9 & 33.4 & 1 \\
\hline Abruzzo & 4.9 & 2.8 & 1.5 & 1.6 & 231.7 & 73.4 & 15 \\
\hline Trentino A. Adige & 4.4 & 5.6 & 1.3 & 2.2 & 229.0 & 156.1 & 16 \\
\hline Latium & 4.3 & 2.7 & 7.9 & 2.1 & -45.9 & 30.3 & 4 \\
\hline
\end{tabular}

Table 2. Domestic market share of Sicilian wines by consumption area

\begin{tabular}{lll}
\hline Year & $\begin{array}{l}\text { Sicily } \\
\text { consumption (\%) }\end{array}$ & $\begin{array}{l}\text { Extra local share } \\
\text { consumption }(\%)\end{array}$ \\
\hline 2006 & 41.6 & 3.1 \\
2007 & 44.8 & 3.3 \\
2008 & 47.6 & 4.5 \\
2009 & 50.5 & 4.4 \\
2010 & 52.4 & 6.6 \\
2011 & 51.7 & 6.8 \\
\hline
\end{tabular}

In view of the market's growing interest in Sicilian wines, we analyze in depth the preferences of Italian consumers with respect to the most important wine segment categories.

This study analyzes the main preferences of Italian consumers with respect to Sicilian wines using a data set from the AC Nielsen Homescan database that reports domestic purchases of wines. The objective of this study is to inform wine stakeholders, professional investors and wine managers about domestic consumer preferences for the attributes of Sicilian wines by evaluating: Objective and/or labelling attributes, such as Geographic origin (GI) information; sensory characteristics associated with wine color; reputation variables, such as brand market penetration and GI designation; and the role of distribution channels. Hedonic price analysis has advanced considerably in recent years in the wine economics literature, both in terms of theoretical insights and applied methodologies (Costanigro et al., 2007; 2010; Panzone, 2011; Kwong et al., 2011; Caracciolo et al., 2013; Roma et al., 2013). Our study suggests a new perspective on this methodology through the implementation of an econometric model using quantile regression (Cameron and Trivedi, 2005; Costanigro et al., 2010) in order to value for each wine segment the implicit price of the attributes affecting wine consumers' choices. The study also focuses on the role of price as an information tool for wines largely purchased by Italian consumers but characterized by limited price fluctuations and by the absence of specific loyalty attributes such as, for example, expert grading.

\section{Theoretical Framework of Hedonic Price Functions: A Brief Literature Review}

Empirical studies focused on consumers'wine preferences have taken into account several sets of intrinsic and extrinsic wine attributes such as price, sensory attributes, geographical origin, labeling, packaging, reputation (Casini et al., 2009; D'Amico et al., 2014b). Among them, price seems to be the most important attribute driving consumer choices. Price not only conveys the amount of money to pay but also plays an important role as an information instrument (Panzone, 2012).

The controversial role of price as a quality signal has now been fully addressed in the economic literature (Monroe, 1973; Rao and Monroe, 1989; Rao, 2005) and despite many authors having shown that labelling or reputation in many cases is the most adequate tool to define the quality of a product (Shapiro, 1983; Caracciolo et al., 2013), the price represents a very important signal that is able to inform consumers about the quality of a product (Wolinsky, 1983).

In view of its importance, price was often the specific objective of the economic literature through hedonic price analysis (Rosen, 1974). Several studies have estimated implicit prices of the attributes and characteristics of wine, showing the importance of the hedonic approach to value the quality attributes of wine (Golan and Shalit, 1993; Nerlove, 1995; Combris et al., 1997; Landon and Smith, 1997). The relationship between price and quality was firstly analyzed by (Golan and Shalit, 1993), whose investigation showed that the pricing system gave a small premium for a better quality grape. Jones and Storchmann (2001) pointed out the relationship between aspects that influence the wine quality and those that influence the wine prices, taking into account subjective quality evaluations and the effects of the age of wines on market prices.

In order to evaluate the effects of quality attributes on wine prices, the current literature on hedonic price has employed three different categories of explanatory variables: The objective characteristics, reputation and sensory characteristics (Benfratello et al., 2009). 
The effect of objective characteristics as determinants of wine prices, such as vintage, alcohol content, geographical origin, grape variety, year, producer size and cellaring potential have been widely verified over the past decade (Combris et al., 1997; 2000; Oczkowski, 1994; Angulo et al., 2000; Steiner, 2004; Almenberg and Dreber, 2011; Roma et al., 2013) in different producer areas, such as France, Australia, Spain and Italy.

Recent studies also suggest that quality descriptors, linked to label characteristics and environmental variables, positively impact the price formation mechanism (Benfratello et al., 2009; Carew and Florkowski, 2010; Kwong et al., 2011). It was determined that even the distribution channel has an influential role in wine price determination as a result of different quality evaluations being assigned to specific sale channels (Steiner, 2004; Costanigro et al., 2007; Brentari et al., 2011; Panzone, 2011).

The impact of producer reputation on prices has been analysed by several authors (Shapiro, 1983; Tirole, 1996); they pointed out how, in a context of imperfect information, reputation systems allow consumers to reduce their cost of gathering information. Producer reputation plays a prominent role in determining wine price (Schamel and Anderson, 2003; Schamel, 2006; Costanigro et al., 2010). For example, the "pricing behavior" of wineries depends in many cases on producers' reputation (Hadj Ali and Nauges, 2008) and several authors have widely demonstrated that a stringent association exists between reputation and the price of wines (Oczkowski, 1994; Ling and Lockshin, 2003; Schamel and Anderson, 2003; Cardebat and Figuet, 2004; Lecocq and Visser, 2006).

In the economic literature, wine reputation depending on wine jury grade has been measured on the basis of experts' opinion, verifying that the evaluation of wine judges is positively correlated to their price, although not all authors agree on their unfailing judgment (Goldstein et al., 2008).

Another important branch of hedonic price studies is strongly connected to the sensory characteristics derived from the chemical components of wine, such as bouquet, acidity, astringency, bitterness etc. The first empirical study on this was carried out by Nerlove (1995), who estimated the price function for imported wine in Sweden taking into account taste attributes (color, aroma, bouquet, acidity, sweetness, body etc.) and chemical variables (sugar, alcohol content, volatile and total acidity, extract, density etc). Combris et al. (1997), by applying a hedonic price technique, showed the influence of objective characteristics appearing on the label of the bottle (color, age, brand) and the sensory characteristics of the wine on the market price of Bordeaux wine. Their findings showed that consumers identify objective characteristics much more easily than sensory characteristics, but at the same time, the quality of a particular wine can be explained by wine jury members in terms of its sensory characteristics. Also, for Burgundy wines (Combris et al., 2000) the results point out that sensory characteristics are less significant than objective characteristics in price formation, with special reference to ranking and vintage. This research highlighted that at the same time taste heterogeneity is irreducible because the grade expressed by a taster is always the result of a compromise and tasting grades are not closely related to price (Combris et al., 2000). Nevertheless, the use of variables linked to the organoleptic and sensory characteristics still remain very common in studies on the hedonic price, reaffirming the "traditional dilemma" on the leading role of price determination between label or objective characteristics and sensory variables (Brentari et al., 2011).

With respect to the methodology for estimating the hedonic price function, the economic literature has shown that different approaches have been used to value the relative contribution of attributes to wine prices. Among them, several approaches have been based on OLS, ordinary least squares regression (Nerlove, 1995; Jones and Storchmann, 2001; Lecocq and Visser, 2006; Costanigro et al,. 2007; Carew and Florkowski, 2010), two-stage least squares regression (Oczkowski, 2001), or the GLS, generalized least squares technique (Hadj Ali and Nauges, 2008).

Some interesting survey design work was carried out through econometric analysis applying a mixed loglinear functional form (Schamel, 2006) by using jointly an ordered probit estimate and a linear estimator (Goldstein et al., 2008), or by a local polynomial regression clustering (Costanigro et al., 2009). Remarkable results were also observed by applying the Box-Cox regression model (Benfratello et al., 2009; Panzone, 2011) and by testing the three most common functional forms (linear, log-linear and $\log -\log$, by means of the RESET test), as in Roma et al. (2013). Finally, we believe that the implicit prices of wine attributes can be analyzed not only on average, which is the case when implementing conventional OLS, but also in the tails of the conditional distribution; that is, at low and/or high values of the wine price. The analysis in the tails can be implemented via quantile regressions, which, besides analyzing the regression model at different points of the conditional distribution, allow us to control the impact of anomalous values on the estimated coefficients.

\section{Data Collection and Methodology}

The methodological approach we adopted in our study was to use an econometric model belonging to the quantile regression class. Domestic wine consumption was analyzed through the application of a hedonic model by gathering information about the purchases of 72,092 households provided by ACNielsen Homescan. The data 
set included 6,593 Italian households that reported yearly household wine purchases for 2011. As our study was focused on Sicilian wines, the data were referred to a random sample of 1,849 household buyers of Sicilian wines $(28 \%$ of the total), representing a total of 5,192 observations (7.2\% of the total acts of buying). Additional information was collected concerning the data set of the offered wines, consisting of 113 Sicilian wineries (out of 1,012 Italian wineries).

This study considers only domestic consumption; it does not consider the HoReCa sales channel (hotel, restaurant and café). The domestic consumption of wine represents $70 \%$ of the quantity and $30 \%$ of the value of the total Italian wine market (Mediobanca, 2013).

Our data on the purchases comprised seven main variables as follows: Price $(€)$, quantities (expressed as liters equivalent), wine typology purchased (white, red and rosé wines), geographic origin of the wines (local consumption: Sicilian wines consumed in Sicily; extralocal: Sicilian wines consumed in all the rest of Italy), sales channels (wine shops and discount sales channels), protected Designation of Origin and Geographical Indication (PDO, PGI) and brand market penetration (defined as the number of brand purchasers compared with the total purchasers, expressed in percent).

We adopted Quantile Regression (QR) as our analytical method. Its suitability is particularly apparent if compared with ordinary least squares regression. While a linear regression curve returns the conditional mean of the distribution corresponding to a set of explanatory variables, QR allows us to calculate different regression curves corresponding to the various points of the distribution and more specifically to each percentile. This method allows us to obtain more detailed information when the economic phenomenon is characterized by the relationship between the dependent variable and the explanatory variables that vary with the sampling distribution.

QR has been widely used in economic research related to alcohol consumption (Manning et al., 1995; Kerr et al., 2006) and household consumption (Ronning and Schulze, 2004), but with the exception of a recent study carried out on the reputation premium (Costanigro et al., 2010) and on the estimation of wine demand among different groups of goods, its application in the wine sector has been very limited. The scarcity of QR knowledge for this important topic in the wine sector justifies our present research.

QR is based on the minimization of the weighted absolute deviations (Cameron and Trivedi, 2005) and it aims to estimate the conditional quantile functions. The $\mathrm{q}^{\text {th }}$ estimator QR minimizes the objective function $\hat{\beta}_{a}$, su $\beta_{a}$ by adopting the linear programming algorithm originally proposed by Armstrong et al. (1979) and generalized by Hunter and Lange (2000):
$Q\left(\beta_{q}\right)=\sum_{i: y_{i} \geq x_{i}^{\prime} \beta}^{N} q\left|y_{i}-x_{i}^{\prime} \beta_{q}\right|+\sum_{i: y_{i}<x_{i}^{\prime} \beta}^{N} 1-q\left|y_{i}-x_{i}^{\prime} \beta_{q}\right|$

where, $0<\mathrm{q}<1 ; \mathrm{e} \beta_{q}$ is defined on $q$, indicating that different values of $\beta_{q}$ are obtained for the different values of $q$ reported in the estimate. Being a semi-parametric estimation, the QR computes the residue through the bootstrap and because of the absence of assumptions about the errors distribution, it is significantly more robust to the outliers as it is not plagued by problems such as heteroskedasticity.

In this case, the opportunity to estimate the different parameters for different percentiles allows us to analyze the price determinants of the Sicilian wine for the different market segments. In the QR model used in this study, the dependent variable is the natural logarithm of the price per liter (lnprz lt) of Sicilian purchased wines. The choice of functional form was based on the results of the "Box-Cox" estimation. The data included in the database were converted into a set of dummies by assigning the value of 1 in the presence of an attribute and a 0 value in its absence. The explanatory variables have been reported in Table 3 .

We identified different categories of attributes classified into four groups: Sensory attributes, such as white and red color; distribution channels, such as discount and specialized wine shops; geographic origin, which took into account the local and extra-local consumption; and finally reputation, which was based on PDO and PGI certification as well as brand market penetration. Concerning extra-local variable we considered all Sicilian wines consumed outside of Sicily while with regard to reputation, although the current literature on hedonic price considers reputation based on expert opinion and on the wine ratings of experts, we consider these two variables to be useful proxies to express wine reputation for basic and popular wines because low priced wines are not included in the guides published by wine experts or in their wine ratings. We assume that the origin designation and market penetration indexes represent adequate measures to capture the wine reputation of the low-priced wines that represent the majority of the wines included in our sample (database).

Table 3. List of the dummy variables usd in QR

\begin{tabular}{|c|c|}
\hline Variables & Description \\
\hline \multicolumn{2}{|l|}{ Reputation } \\
\hline Origin designation & 1 if PDO/PGI \\
\hline Penetration index & index of brand market penetration \\
\hline \multicolumn{2}{|l|}{ Distribution channel } \\
\hline Wine shop & 1 if wine shop \\
\hline Discount & 1 if discount \\
\hline \multicolumn{2}{|l|}{ Sensory attributes } \\
\hline White wine & 1 if white \\
\hline Red wine & 1 if red \\
\hline \multicolumn{2}{|l|}{ Geographic origin } \\
\hline Local consumption & 1 if regional consumption \\
\hline Extra-local consumption & 1 if Extra-regional consumption \\
\hline Constant & Intercept \\
\hline
\end{tabular}




\section{Results}

This section presents the results of the quantile regression carried out on a sample of 5,192 observations that have been reported in Table 4 .

Parameters were estimated for each of the different (levels of) percentiles in order to verify the implicit prices of attributes with respect to different segments of wine classes.

The representation of the results allows us to observe the performance of the estimated coefficients for each explanatory variable by varying the quantiles from 0 to 1. Furthermore, the confidence intervals indicate the robustness of the results obtained by increasing the value of the quantiles.

The parameter related to brand penetration provides information about brand reputation that is linked to and summarizes, the price premium that the brand receives.

In particular, it is positively associated to price for the lowest market segments of wines, whereas as the price increases, as shown in the percentiles included between 0.5 and 0.9 , it is negatively associated to price for the highest segments of wines.

The graphical representations summarized in Fig. 1 allow us to identify the coefficient and confidence intervals for each of the explanatory variables taken into account.

According to our result concerning the evaluation of marketing channels, we consider that it is appropriate to undertake a joint analysis of the most relevant trends. As reported in the estimates of two parameters, wine shops and discount sales outlets represent marketing channels that are diametrically opposed.

With regard to wine shops, we find that only the lowest wine category among those considered (0.1) shows a negative correlation with the price range, while as the percentiles increase the role of wine shops progressively become more significant in the determination of the respective prices, reaching the highest value in the last percentile (0.9). This result confirms the positive correlation of wine shops in price fixation, whereas discount have not a significant role in each of the price ranges examined, showing increasing negative values in all estimated quantiles (0.1-0.9). Our findings emphasize how discount sales of Sicilian wines receive an increasingly negative price premium; that is, the wines with the highest price ranges are progressively and strongly negatively affected by this specific form of distribution channel.

Although previous studies considered the color of wine to be an objective attribute (Combris et al., 1997; Cardebat and Figuet, 2004; Roma et al., 2013), according to Nerlove (1995) we consider the color of wine to be chemical characteristics and as such it appears to be strongly linked to sensory attributes.

With regard to the main typology of Sicilian wines, differentiated on the basis of color, we can observe that the Italian consumer appears more centered on the white wines as the red wines are marked with a negative coefficient in all market segments considered. As a consequence, although Sicily has a traditional propensity towards the production of red wines, surprisingly white wines seem to characterize the consumption of the intermediate wine segments considered $(0.25-0.75)$. This result is consistent with previous studies affirming the different implicit prices between red and white wines (Costanigro et al., 2010; Carew and Florkowski, 2010).

With regard to the consumption areas, which are regionally differentiated as local and extra-local, there is some evidence that differences in food consumption patterns between northern and southern Italy are not very marked, confirming a previous study (Di Vita et al., $2013 b)$. In fact, consumption in both areas of the country focuses on low-end products $(0.1$ and 0.25$)$. However, in the extra-local area, consumption loses relevance with increasing price levels (0.5-0.9), whereas at the local level we observe a more widespread consumption. This is probably due to the fact that local wine enjoys its highest reputation within its production area for almost all price ranges, with the only negative exception being for the highest percentile (0.9).

Table 4. Results of Quantile regression and OLS

\begin{tabular}{|c|c|c|c|c|c|c|}
\hline & 0.1 & 0.25 & 0.5 & 0.75 & 0.9 & OLS \\
\hline \multicolumn{7}{|l|}{ Reputation } \\
\hline PDO/PGI & $0.297 * * *$ & $0.475 * * *$ & $0.701 * * *$ & $0.952 * * *$ & $0.962 * * *$ & $0.674 * * *$ \\
\hline Penetration & $0.009 * * *$ & 0.004 & $-0.039 * * *$ & $-0.024 * * *$ & $-0.061 * * *$ & $-0.024 * * *$ \\
\hline \multicolumn{7}{|l|}{ Distribution channel } \\
\hline Wine shop & -0.080 & $0.247 * * *$ & $0.434 * * *$ & $0.555 * * *$ & $0.698 * * *$ & $0.292 * * *$ \\
\hline Discount & $-0148 * * *$ & $-0.170 * * *$ & $-0.447 * * *$ & $-707 * * *$ & $-0.883 * * *$ & $-0.465 * * *$ \\
\hline \multicolumn{7}{|l|}{ Sensory attributes } \\
\hline White wine & 0.045 & $0.210 * * *$ & $0.231 * * *$ & $0.237 *$ & $0.113 * * *$ & $0.217 * * *$ \\
\hline Red Wine & $-0.078 * *$ & -0.028 & -0.007 & -0.001 & $-0.154 * * *$ & -0.046 \\
\hline \multicolumn{7}{|l|}{ Geographic origin } \\
\hline Local Consumption & $0.039 * *$ & $0.098 * *$ & 0.020 & 0.019 & -0.042 & $0.047 * *$ \\
\hline Extra-local consumption & $0.026 * * *$ & 0.033 & $-0.054 *$ & $0.073 * * *$ & -0.024 & -0.001 \\
\hline Constant & 0.022 & -0.006 & $0.302 * * *$ & $0.590 * * *$ & $1.115 * * *$ & $0.389 * * *$ \\
\hline
\end{tabular}



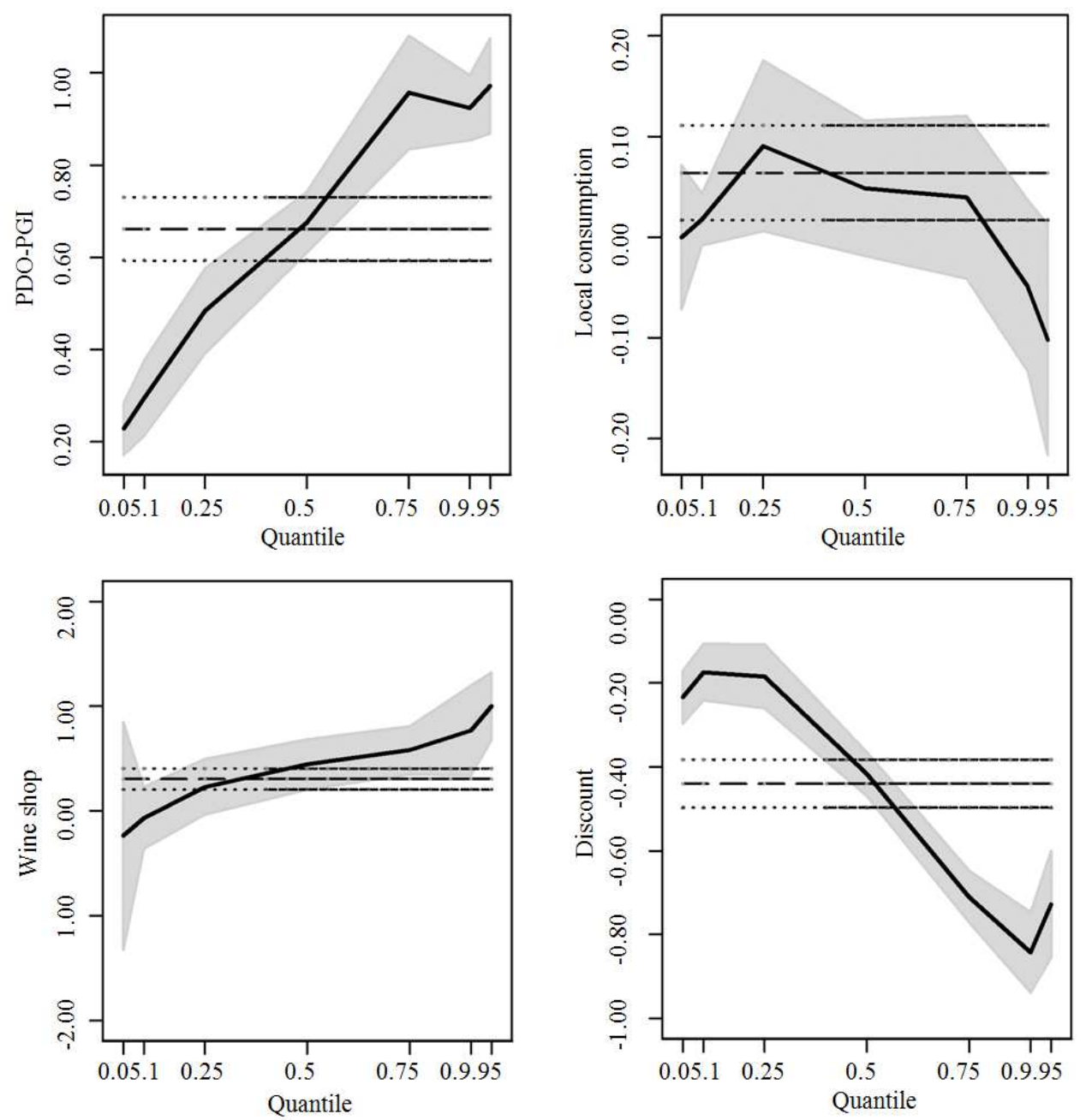

Fig. 1. Estimated coefficients of the quantile regression and confidence interval for selected explanatory variable-quantile form 0 to 1

\section{Discussion}

The wines certified as PDO and PGI always receive a premium price as these certifications are perceived as quality indicators and the values of the coefficients grow increasingly as the price level of the wines rises.

This appears to be consistent with a previous study that argued in favor of the economic viability of the PDO label in "high reputation regions", whereas the interaction between region and denomination of origin allows producers to charge a premium (Panzone and Simoes, 2009), confirming that consumers interested in PDO and PGI wines are strongly price-sensitive and they acknowledge the justification for a premium price for certified wines.

By analyzing the estimates of brand market penetration we found that this indicator in most cases reveals a high significance. This implies that the brand reputation of Sicilian wineries operating in the Italian market is more appreciated for the basic wines segments.
Concerning trade flows, previous studies pointed out the importance of distribution channels in price fixation, highlighting that pricing strategies are strongly related to the specific distribution channels (Steiner, 2004; Panzone, 2011; Brentari et al., 2011). Our result confirms that the wine shops directly impact on price fixation, highlighting the presence of a premium price for high quality wines, whereas discount sales do not appear to have a significant role in price formation. This result is consistent with those of Brentari et al. (2011), who argue that large retail distribution provides wine consumers with a lower level of quality intrinsic characteristics, confirming that large-scale retail plays a marginal role in the price formation of the high-end wines and verifying at the same time the existence of implicit values of wine attributes associated with the specialists wine shops, as previously suggested (Panzone, 2011).

The domestic Sicilian wine market seems to suffer from the competition from wines coming from other regions of Italy, especially for the highest price segment. 
However, in the extra-regional market Sicilian wines benefit from a higher price premium than in the regional market. This result could highlight the inability of the local market to convey information about price formation for premium wines or a lack of the ability of local consumers to adequately value the regional origin of its own wines. This last finding seems to not confirm previous findings (Ling and Lockshin, 2003; Steiner, 2004), who argued that there is a direct relationship between the region of origin and wine prices, at least for the highest quantiles.

\section{Conclusion}

The fast and deep modifications of markets require a continuous and close attention to the analysis of consumer preferences; these are crucial elements for the strategic planning of wineries (Cembalo et al., 2014; Cicia et al., 2013; Caracciolo and Lombardi, 2012).

During the past decade, Sicilian wines have been successful in gaining new market segments, revealing a growing consumer fulfillment. We identified the Sicilian wine industry as a case study because of its booming expansion, both in terms of quantity and quality, allowing us to detect specific dynamics in its hedonic price mechanism.

In order to better address the question of the effect of implicit value variables on wine prices, our study focused on the different attributes of Sicilian wines that could generate a competitive advantage as well as a specific premium price for the wineries, thereby providing a direct measure of the appreciation of Italian consumers.

Our results indicate that the market potential of Sicilian wines is increasingly growing (its market share has more than doubled) and given that the Italian wine market is one of the most interesting because of its high consumption per capita, our findings could be useful for companies that have already invested in Sicilian wine areas/production as well as those that are considering whether to invest.

The results derived from this study provide a useful contribution to the understanding of implicit wine prices for wineries, especially the large wineries and those closely associated with the geographical territory.

Our findings reveal the strong interest of consumers in the lower-priced segment for noncertified wine as well an interest in certified wines (PDO and PGI wines), which still constitute only a barely relevant part of total regional production. The combination of all these factors implies further market growth for the Sicilian wine industry.

With respect to the most meaningful attributes that contribute to the implicit price of wines, our results indicate that certification according to PDO and PGI designation is the main determinant in the wine price mechanisms; certified wines achieve premium prices that are progressively higher as the price level of the wine increases. Furthermore, the effect of brand enforcement on price formation seems to be very significant for lowend wines, whereas its effects have no specific impact on the price mechanism for the high-end wines.

Important findings were also related to the distribution channels. The results confirmed that the place of selling plays a very important role in the hedonic pricing of wines, highlighting the presence of a premium price for high-end wines sold at wine shops.

Our study also contributes to the debate about the methodology to be used for the estimation of hedonic prices, suggesting that our quantile regression approach is an efficient solution to the distortion of the estimates due to heteroskedasticity of the sample. In view of this, we can argue that a contribution exists for each wine attribute in price fixation and the impact differs as the price range changes, thus confirming the presence of different implicit prices for different quantiles. Finally, this study provides some empirical evidence that quantile regression allows us to observe more important, detailed information for specific price ranges; this information could be lost by simply applying the OLS method.

Our present study also has implications for wine market segmentation. In particular, our results suggest that the wide heterogeneity of wine product categories requires a detailed evaluation of wine attributes for homogenous and standardized classes, thereby confirming the results of Costanigro et al. (2009).

The principal limitation of our research relates to our reliance on a limited data set that takes into account only purchases at large retail distribution centres and does not consider the "dynamics" of wines sold through the HoReCa channel; this is a channel that represents a very important chain for the premium, ultra-premium and icon wine segments (D'Amico et al., 2014a). As a consequence, further research should be carried out in order to better understand the consumer behavior with respect to each wine category and each selling place. Furthermore, our findings suggest that greater efforts should be made to improve the pricing behavior of wine companies; at present Sicilian wineries seem to be involved in investing in their private brands, thereby undervaluing the potential to promote the peculiarities of territory and the reputation of the "Sicilian brand".

\section{Acknowledgement}

We are indebted to the Agriculture Department of the Sicilian Regional Government for financial support.

\section{Funding Information}

This study is part of the research project "Analisi economico-gestionali della filiera vitivinicola in Sicilia e 
valorizzazione delle produzioni" financed by Regione Siciliana and directed by Professor Mario D'Amico.

\section{Author's Contributions}

All five authors have equally contributed in the preparation, development and publication of this manuscript.

\section{Ethics}

No any ethical issues are expected to arise after the publication of this manuscript.

\section{References}

AC Nielsen, 2011. Home scan data.

Almenberg, J. and A. Dreber, 2011. When does the price affect the taste? Results from a wine experiment. J. Wine Econom., 6: 110-121. DOI: $10.1017 / \mathrm{S} 1931436100001085$

Angulo, A.M., J.M. Gil, A. Gracia and M. Sanchez, 2000. Hedonic prices for Spanish red quality wine. British Food J., 102: 481-493. DOI: $10.1108 / 00070700010336445$

Armstrong, R.D., E.L. Frome and D.S. Kung, 1979. Algorithm 79-01: A revised simplex algorithm for the absolute deviation curve fitting problem. Commun. Stat. Simulat., 8:175-190.

Bellia, C., 2007. Strategies of improvement of marketing mix in the Sicilian market oriented wine entrerprises. New Medit., 2: 27-37.

Benfratello, L., M. Piacenza and S. Sacchetto, 2009. Taste or reputation: What drives market prices in the wine industry? Estimation of a hedonic model for Italian premium wines. Applied Econom., 41: 2197-2209. DOI: 10.1080/00036840701222439

Brentari, E., R. Levaggi and P. Zuccolotto, 2011. Pricing strategies for Italian red wine. Food Quality Preference, 22: 725-732.

DOI: $10.1016 /$ j.foodqual.2011.06.001

Cameron, A.C. and P.K. Trivedi, 2005. Microeconometrics: Methods and Applications. 1st Edn., Cambridge University Press, Cambridge, ISBN-10: 0521848059, pp: 1034.

Caniglia, E., M. D'Amico and I. Peri, 2008. An analysis of consumers' perception of the quality of the Etna DOC wine. New Medit., 3: 32-40.

Caracciolo, F. and P. Lombardi, 2012. A newinstitutional framework to explore the trade-off between Agriculture, Environment and Landscape. Econom. Policy Energy Environ., 3: 135-154. DOI: 10.3280/EFE2012-003009

Caracciolo, F., L. Cembalo and E. Pomarici, 2013. The hedonic price for an Italian grape variety. Italian J. Food Sci., 25: 289-294.
Cardebat, J.M. and J.M. Figuet, 2004. What explains Bordeaux wine prices? Applied Econom. Lett., 11: 293-296. DOI: 10.1080/1350485042000221544

Carew, R. and W.J. Florkowski, 2010. The importance of geographic wine appellations: Hedonic pricing of burgundy wines in the British Columbia wine market. Canadian J. Agric. Econom., 58: 93-108. DOI: $10.1111 /$ j.1744-7976.2009.01160.x

Casini, L., A.M. Corsi and S. Goodman, 2009. Consumer preferences of wine in Italy applying best-worst scaling. Int. J. Wine Business Res., 21: 64-78. DOI: 10.1108/17511060910948044

Chinnici, G., B. Pecorino, M. Rizzo and P. Rapisarda, 2013. Evaluation of the performances of wine producers in Sicily. Quality-Access Success, 14: 108-135.

Cembalo, L., F. Caracciolo and E. Pomarici, 2014. Drinking cheaply: The demand for basic wine in Italy. Aust. J. Agr. Resour. Econom., 58: 374-391. DOI: $10.1111 / 1467-8489.12059$

Cicia, G., L. Cembalo, T. Del Giudice and R. Scarpa, 2013. Country-of-origin effects on Russian wine consumers. J. Food Prod. Market., 19: 247-260. DOI: $10.1080 / 10454446.2013 .724369$

Combris, P., S. Lecocq and M. Visser, 1997. Estimation of a hedonic price equation for Bordeaux wine: Does quality matter? Economic J., 107: 390-402. DOI: $10.1111 / \mathrm{j} .0013-0133.1997 .165 . \mathrm{x}$

Combris, P., S. Lecocq and M. Visser, 2000. Estimation of a hedonic price equation for Burgundy wine. Applied Econom., 32: 961-967. DOI: $10.1080 / 000368400322011$

Costanigro, M., J.J. McCluskey and R.C. Mittelhammer, 2007. Segmenting the wine market based on price: Hedonic regression when different prices mean different products. J. Agric. Econom., 58: 454-466. DOI: $10.1111 /$ j.1477-9552.2007.00118.x

Costanigro, M., R.C. Mittelhammer and J.J. McCluskey, 2009. Estimating class-specific parametric models under class uncertainty: Local polynomial regression clustering in an hedonic analysis of wine markets. J. Applied Econometr., 24: 1117-1135. DOI: $10.1002 /$ jae. 1094

Costanigro, M., J.J. McCluskey and C. Goemans, 2010. The economics of nested names: Name specificity, reputations and price premia. Am. J. Agric. Econom., 92: 1339-1350. DOI: 10.1093/ajae/aaq065

D'Amico, M., G. Di Vita and G. Bracco, 2014a. Direct sale of agro-food product: The case of wine in Italy. Quality-Access Success, 15: 247-253.

D’Amico, M., G. Di Vita, G. Chinnici, G. Pappalardo and B. Pecorino, 2014b. Short food supply chain and locally produced wines: Factors affecting consumer behavior. Italian J. Food Sci., 26: 329-334. 
D’Amico, M., G. Chinnici, G. Pappalardo and G. Di Vita, 2011. Analisi sul consumo di vino siciliano in Italia. In Economia Del Vino in Sicilia, D'Amico, M. (Ed.), Bonanno, Acireale, ISBN-10: 8877968729.

Di Vita, G., G. Chinnici and M. D'Amico, 2014a. Clustering attitudes and behaviours of Italian wine consumers. Quality-Access Success, 15: 54-61.

Di Vita, G., G. Chinnici, G. Pappalardo, M. D'Amico and S. Bracco, 2014b. Standard output versus standard gross margin, a new paradigm in the EU farm economic typology: What are the implications for wine-grape growers?. J. Wine Res., 25: 229-242.

Di Vita, G., C. Bellia, G. Pappalardo and M. D'Amico, 2013a. The role of innovation and organization in small size wineries: The case of Malvasia delle Lipari PDO wine. Quality-Access Success, 14: 107-112.

Di Vita, G., M. D’Amico, G. La Via and E. Caniglia, 2013b. Quality perception of PDO extra-virgin olive oil: Which attributes most influence Italian consumer? Agric. Econom. Rev., 14: 46-58.

Golan, A. and H. Shalit, 1993. Wine quality differentials in hedonic grape pricing. J. Agric. Econom., 44: 311-321. DOI: 10.1111/j.1477-9552.1993.tb00274.x

Goldstein, R., J. Almenberg, A. Dreber, J.W. Emerson and A. Herschkowitsch et al., 2008. Do more expensive wines taste better? Evidence from a large sample of blind tastings. J. Wine Econom., 3: 1-9. DOI: $10.1017 / \mathrm{S} 1931436100000523$

Hadj Ali, H. and C. Nauges, 2008. The pricing of experience goods: The example of en primeur wine. Am. J. Agric. Econom., 89: 91-103. DOI: $10.1111 / \mathrm{j} .1467-8276.2007 .00965 . x$

Hunter, D.R. and K. Lange, 2000. Quantile regression via an MM algorithm. J. Comput. Graph. Stat., 9: 60-77.

Jones, G.V. and K.H. Storchmann, 2001. Wine market prices and investment under uncertainty: An econometric model for Bordeaux crus classes. Agric. Econom., 26: 115-133. DOI: $10.1111 /$ j.1574-0862.2001.tb00058.x

Kerr, W.C., T.K. Greenfield and L.T. Midanik, 2006. How many drinks does it take you to feel drunk? Trends and predictors for subjective drunkenness. Addiction, 101: 1428-1437. DOI: $10.1111 /$ j.1360-0443.2006.01533.x

Kwong, L.M.K., D. Cyr, J. Kushner and T. Ogwang, 2011. A semiparametric hedonic pricing model of Ontario wines. Canadian J. Agric. Econom., 59: 361-381. DOI: 10.1111/j.1744-7976.2010.01209.x

Landon, S. and C.E. Smith, 1997. The use of quality and reputation indicators by consumers: The case of Bordeaux wine. J. Consumer Policy, 20: 289-323. DOI: $10.1023 / \mathrm{A}: 1006830218392$

Lecocq, S. and M. Visser, 2006. What determines wine prices: Objective vs. sensory characteristics. J. Wine Econom., 1: 42-56.

DOI: $10.1017 / \mathrm{S} 1931436100000080$
Ling, B.H. and L. Lockshin, 2003. Components of wine prices for Australian wine: How winery reputation, wine quality, region, vintage and winery size contribute to the price of varietal wines. Aus. Market. J., 11: 19-31.

DOI: $10.1016 / \mathrm{S} 1441-3582(03) 70132-3$

Manning, W.G., L. Blumberg and L.H. Moulton, 1995. The demand for alcohol: The differential response to price. J. Health Econom., 14: 123-148. DOI: $10.1016 / 0167-6296(94) 00042-3$

Mediobanca, 2013. Indagine sul settore vinicolo. MBRES, Ufficio studi Mediobanca, Milano.

Monroe, K.B., 1973. Buyers' subjective perceptions of price. J. Market. Res., 10: 70-80. DOI: $10.2307 / 3149411$

Nerlove, M., 1995. Hedonic price functions and the measurement of preferences: The case of Swedish wine consumers. Eur. Econom. Rev., 39: 1697-1716. DOI: 10.1016/0014-2921(95)00013-5

Oczkowski, E., 1994. Hedonic price function for Australian premium table wine. Aus. J. Agric. Econom., 38: 93-110. DOI: $10.1111 /$ j.1467-8489.1994.tb00721.x

Oczkowski, E., 2001. Hedonic wine price functions and measurement error. Econom. Record, 77: 374-382. DOI: $10.1111 / 1475-4932.00030$

Panzone, L.A., 2011. The lost scent of Eastern European wines in Western Europe: A hedonic model applied to the UK market. Brit. Food J., 113: 1060-1078. DOI: $10.1108 / 00070701111153797$

Panzone, L.A., 2012. Alcohol tax, price-quality proxy and discounting: A reason why alcohol taxes may rebound. J. Agric. Econom., 63: 715-736. DOI: $10.1111 /$ j.1477-9552.2012.00351.x

Panzone, L.A. and O.M. Simões, 2009. The importance of regional and local origin in the choice of wine: Hedonic models of Portuguese wines in Portugal. J. Wine Res., 20: 27-44. DOI: $10.1080 / 09571260902978527$

Rao, A.R., 2005. The quality of price as a quality cue. J. Market. Res., 42: 401-405. DOI: $10.1509 / \mathrm{jmkr} .2005 .42 .4 .401$

Rao, A.R. and K.B. Monroe, 1989. The effect of price, brand name and store name on buyers' perceptions of product quality: An integrative review. J. Market. Res., 26: 351-357. DOI: 10.2307/3172907

Roma, P., G. Di Martino and G. Perrone, 2013. What to show on the wine labels: A hedonic analysis of price drivers of Sicilian wines. Applied Econom., 45: 2765-2778. DOI: 10.1080/00036846.2012.678983

Ronning, G. and N. Schulze, 2004. A microeconometric characterization of household consumption using quantile regression. Applied Econom. Q., 50: 183-208.

Rosen, S., 1974. Hedonic prices and implicit markets: Product differentiation in pure competition. J. Political Economy, 82: 34-55. DOI: 10.1086/260169 
Schamel, G. and K. Anderson, 2003. Wine quality and varietal, regional and winery reputations: Hedonic prices for Australia and New Zealand. Econom. Record, 79: 357-369.

DOI: $10.1111 / 1475-4932.00109$

Schamel, G., 2006. Geography versus brands in a global wine market. Agribusiness, 22: 363-374. DOI: 10.1002/agr.20091

Shapiro, C., 1983. Premiums for high quality products as returns to reputations. Q. J. Econom., 98: 659-679. DOI: $10.2307 / 1881782$
Steiner, B.E., 2004. Australian wines in the British wine market: A hedonic price analysis. Agribusiness, 20: 287-307. DOI: 10.1002/agr.20012

Tirole, J., 1996. A Theory of Collective Reputations (with applications to the persistence of corruption and to firm quality). Rev. Econom. Stud., 63: 1-22. DOI: $10.2307 / 2298112$

Wolinsky, A., 1983. Prices as signals of product quality. Rev. Econom. Stud., 50: 647-658.

DOI: $10.2307 / 2297767$ 